
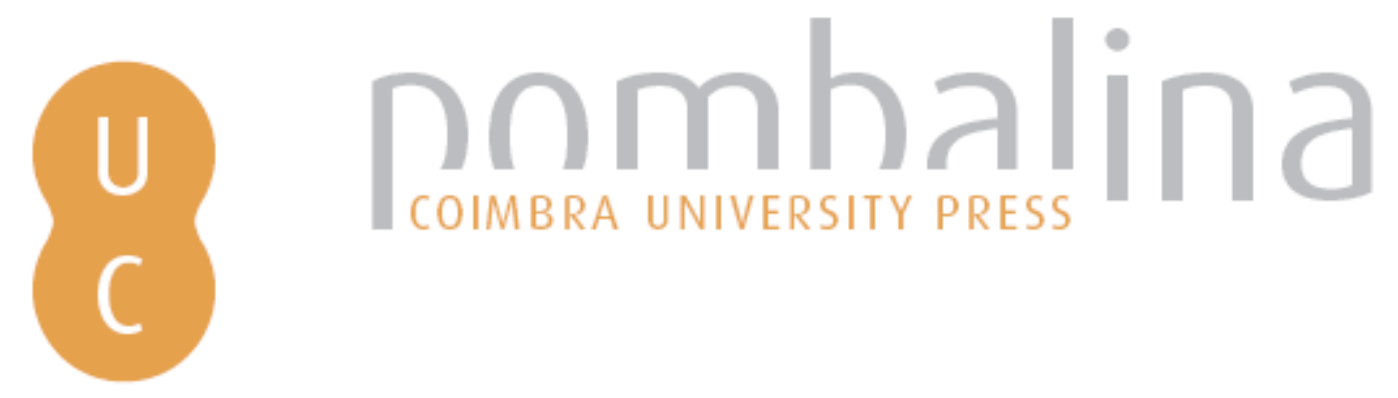

Electra, Dios y Galdós: comparativa y temática de una Electra en los albores del siglo
XX

Autor(es): $\quad$ L. Lapeña, Alejandro

Publicado por: Imprensa da Universidade de Coimbra

URL

persistente: URI:http://hdl.handle.net/10316.2/44010

DOI: $\quad$ DOl:https://doi.org/10.14195/978-989-26-1550-9_8

Accessed : $\quad$ 26-Apr-2023 12:13:37

A navegação consulta e descarregamento dos títulos inseridos nas Bibliotecas Digitais UC Digitalis, UC Pombalina e UC Impactum, pressupõem a aceitação plena e sem reservas dos Termos e Condições de Uso destas Bibliotecas Digitais, disponíveis em https://digitalis.uc.pt/pt-pt/termos.

Conforme exposto nos referidos Termos e Condições de Uso, o descarregamento de títulos de acesso restrito requer uma licença válida de autorização devendo o utilizador aceder ao(s) documento(s) a partir de um endereço de IP da instituição detentora da supramencionada licença.

Ao utilizador é apenas permitido o descarregamento para uso pessoal, pelo que o emprego do(s) título(s) descarregado(s) para outro fim, designadamente comercial, carece de autorização do respetivo autor ou editor da obra.

Na medida em que todas as obras da UC Digitalis se encontram protegidas pelo Código do Direito de Autor e Direitos Conexos e demais legislação aplicável, toda a cópia, parcial ou total, deste documento, nos casos em que é legalmente admitida, deverá conter ou fazer-se acompanhar por este aviso.

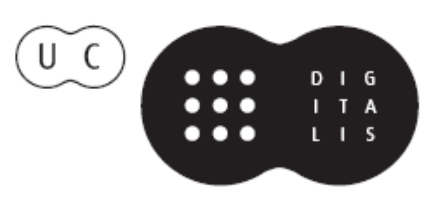




\section{Desplazamientos de la tradición clásica en las culturas hispánicas}

Paola Bellomi, Claudio Castro Filho, Elisa Sartor (eds.)

IMPRENSA DA UNIVERSIDADE DE COIMBRA 


\title{
Electra, Dios y Galdós: comparativa y temática de una ELECTRA EN LOS ALBORES DEL SIGLO XX
}

(Electra, God and Galdós: comparison and themes of a Electra at the dawn of $20^{\text {th }}$ century)

\author{
Alejandro L. Lapeña \\ Investigador autónomo (Orcid: 0000-0001-9460-075X)
}

\begin{abstract}
Resumen: A pesar de que el mito de Electra ha sido tratado en numerosas ocasiones a lo largo de la historia por autores como Esquilo, Sófocles, Eurípides, Séneca, Giraudoux, O’Neill, Nelson Rodrigues, la Electra de Galdós es una versión muy personal de mito, tanto que pudiera parecer a simple vista que nada queda de la princesa griega en su obra. Sin embargo, nos encontramos con una obra que bebe de las fuentes clásicas sin olvidar la realidad social de su tiempo: una España entre la tradición y la modernidad, entre la religión y la ciencia con Dios de telón de fondo.
\end{abstract}

Palabras clave: Pérez Galdós, Electra, religión y ciencia, reformulación del mito.

Aвstract: Although Electra's myth has been addressed and portrayed many times throughout history by authors such as Aeschylus, Sophocles, Euripides, Seneca, Giraudoux, O’Neill and Nelson Rodrigues, Galdós' Electra is a very personal version of the myth. So much indeed that at first glance it might seem that nothing of the Greek princess remains in his work. Nevertheless, this work draws on the classical sources while being aware of the social reality of its time: a Spain torn between tradition and modernity, between religion and science, with God in the background.

Keywords: Pérez Galdós, Electra, religion and science, reformulation of the myth.

\section{Antecedentes: las Electras clásicas}

Si vamos a hablar de Electra como mito, es lógico remontarnos a las que podemos considerar las "Electras fundacionales" como son la de Sófocles y la de Eurípides, aunque existan otras muchas versiones posteriores como la de Girandoux, la de O'Neill (A Electra le sienta bien el luto) o las brasileñas de Nelson Rodrigues (Álbum de familia y Senhora dos Afogados), amén de la de Pérez Galdós, que será analizada en el presente capítulo. Ambas versiones clásicas relatan la misma historia: la venganza de los príncipes Electra y Orestes contra su madre, Clitemnestra, que asesinó a su padre, Agamenón, cuando volvió de Troya para poder quedarse así con su amante extranjero, Egisto, y poder vengar la muerte de su hija Ifigenia, que fue sacrificada por Agamenón antes de partir a Troya para conseguir buenos vientos. Sin embargo, existen diferencias bastante significativas que resumimos a continuación. 
Sófocles nos presenta a una Electra soltera que aún vive en el palacio de la familia, ahora encabezada por Egisto, el amante de Clitemnestra. Asimismo, en esta tragedia aparece el personaje de Crisótemis, la hermana de Electra, que es más transigente con el adulterio materno.

Por su parte, Eurípides nos muestra a una Electra que vive exiliada en el campo y casada con un campesino de pobre condición, del que no está enamorada. Sin embargo, este respeta esta ausencia de amor y su matrimonio no ha sido consumado, por lo que, al igual que en la versión de Sófocles, nos encontramos con una Electra virgen. Además, encontramos a un Orestes mucho más dubitativo con el hecho de matar a su madre. Asimismo, este final es mucho más amargo: Orestes debe huir por haber derramado la sangre de su madre y los hermanos, nuevamente después de tantos años, deben volver a separarse.

Según Finkenthal (1980: 136-137), la Electra de Galdós bebe mucho más de la de Eurípides, ya que esta obra criticaba más las condiciones de vida de la mujer ateniense y atacaba abiertamente el oscurantismo y las falsas convenciones, mientras que la de Sófocles se decanta más por una dialéctica entre el destino y el carácter. Sin embargo, aunque concordamos con esta visión, es cierto que Pérez Galdós consigue distanciarse mucho de la herencia clásica de la obra, como veremos más adelante.

\section{Contexto históRico}

La Electra de Pérez Galdós se estrena en 1901. Estamos hablando de una época muy convulsa para España con la reciente pérdida de las colonias (1898) y todo lo que ello supuso a diversos niveles tanto económico como social. Asimismo, España está en un momento de profunda crisis política con la muerte de Cánovas (1897) (López Nieto 1990: 717-721).

No obstante hay tres hechos que influyen tanto en la concepción de la obra como en su posterior éxito (como veremos más adelante) como son el proyecto de matrimonio de la princesa de Asturias María de las Mercedes de Borbón y Austria, hermana del rey Alfonso XIII, con su primo, el príncipe Carlos de Borbón, ya que los liberales no veían con buenos ojos que su padre hubiera luchado con los carlistas durante la Tercera Guerra Carlista dado que, en caso de que la princesa llegara al trono, la protección de los principios constitucionales no estaban asegurados; la discusión de la Ley de Asociaciones o el famoso, en la época, caso Adelaida Ubao (López Nieto 1990: 711).

Este último hecho es muy importante para entender la obra. Resumido de forma muy sucinta, Adelaida Ubao fue una joven que fue persuadida por un jesuita para ingresar en el convento frente a la opinión familiar. El caso tuvo un gran calado en la época y obligó a modificar la Ley de Asociaciones Religiosas y, según autores como Iglesias Zoido (2006: 462) o Finkenthal (1980: 135), la representación de la obra parece haber sido decisiva para la sentencia final sobre 
el caso, que fue contraria a la orden jesuita. Esto coincide en el tiempo con un profundo sentimiento contra los abusos de los clericales que estaban en el Gobierno y el contraataque de la jerarquía eclesiástica, como puede verse en la marcha de los niños de Valencia en febrero de 1901 (Finkenthal 1980: 114).

Asimismo, hubo circunstancias personales del propios Galdós que influyeron en su concepción como fue su ruptura con la actriz fracasada y judía conversa Concha [Ruth] Morell, cuya relación, según algunos biógrafos, fue simultánea con las que tuvo con otras mujeres como Lorenza Corbián (Escolar 1989) o la propia escritora Emilia Pardo Bazán —Iglesias Zoido (2006: 461) ve una clara influencia intertextual de la obra La madre naturaleza (1887) de Pardo Bazán en Electra - . La relación con Concha [Ruth] Morell fue tortuosa y ella le había amenazado con que, cuando la dejara, se metería a monja, por lo que, según algunos autores como Ávila Arellano (1992: 837), se produce una más que notable identificación entre Electra y Concha, ya que ambas vivieron con parientes en el País Vasco (Electra en Hendaya y Concha en San Sebastián), sus madres tuvieron una vida disoluta, rompieron con sus familias y luego se arrepintieron y murieron en sendos conventos (la de Electra en San José de la Penitencia y la de Concha en las Hermanitas de las Pobres). Además, ambas hablaban francés y eran aficionadas a la pintura.

\section{Electra, de Pérez Galdós}

Electra, de Pérez Galdós, cuenta la historia de una muchacha huérfana llamada Electra, de padre desconocido y madre muerta cuya vida disoluta la llevó a arrepentirse de sus pecados e internarse en el convento de San José de la Penitencia alrededor de 1888, donde falleció en 1895. Así pues, Electra ha estado viviendo en Hendaya con sus parientes, hasta que es acogida por la prima hermana de su madre, Evarista, y su marido, Urbano Yuste, ambos de familia acomodada. A cargo de la gestión de los negocios de los Yuste está el Sr. Cuesta y al frente de la dirección espiritual de la pareja se encuentra Salvador Pantoja, un clérigo inflexible con unas ideas bastante conservadoras sobre la educación de Electra, que esta rechaza. Lo interesante de estos personajes es que ambos dejan entrever que son el verdadero padre de Electra en sendas conversaciones con ella:

Cuesta. [...] Electra, he pensado mucho en usted antes que la trajeran a Madrid, y al verla ¡Dios mío!, he pensado, he sentido... qué sé yo... un dulce afecto, el más puro de los afectos, mezclado con alaridos de mi conciencia.

Electra. (Aturdida.) ¡La conciencia! ¡Qué cosa más grave debe ser! La mía es como un niño que está todavía en la cuna.

Cuesta. (Con tristeza.) La mía es vieja, memoriosa. Me repite, me señala sin cesar los grandes errores de mi vida.

Electra. ¡Usted... errores graves usted tan bueno!

Cuesta. Sí, sí; bueno, bueno... y pecador... En fin, dejemos los errores y vamos 
a sus consecuencias. Yo no quiero, no, que usted viva desamparada. Usted no posee bienes de fortuna. Es dudoso que la protección de Urbano y Evarista sea constante. ¿Cómo he de consentir yo que se encuentra usted pobre y desvalida el día de mañana?

Electra. (Con penosa lucha entre su conocimiento y su inocencia.) No sé si lo entiendo... no sé si debo entenderlo. (Electra I, ix)

Pantoja. No. Cuando me envilecí, cuando me encenagué en el pecado, no había usted nacido.

Electra. Pero nací...

Pantoja. (Después de una pausa.) Cierto...

Electra. Nací... Por Dios, señor de Pantoja, acabe usted pronto...

Pantoja. Su turbación me indica que debemos apartar los ojos del pasado. E1 presente es para usted muy satisfactorio.

Electra. ¿Por qué?

Pantoja. Porque en mí tendrá usted un amparo, un sostén para toda la vida. Inefable dicha es para mí cuidar de un ser tan noble y hermoso defender a usted de todo daño, guardarla, custodiarla, dirigirla, para que se conserve siempre incólume y pura; para que jamás la toque ni la sombra ni el aliento del mal. Es usted una niña que parece un ángel. No me conformo con que usted lo parezca; quiero que lo sea.

Electra. (Fríamente.) Un ángel que pertenece a usted... ¿Y en esto debo ver un acto de caridad extraordinaria, sublime?

Pantoja. No es caridad: es obligación. A mi deber de ampararte, corresponde en ti el derecho de ser amparada. (Electra I, xi)

Pantoja. Amo a Electra con un amor tan intenso, que no aciertan a declararlo todas las sutilezas de la palabra humana. Desde que la vieron mis ojos, la voz de la sangre clamó dentro de mí, diciéndome que esa criatura me pertenece... Quiero y debo tenerla bajo mi dominio santamente, paternalmente... Que ella me ame como aman los ángeles... Que sea imagen mía en la conducta, espejo mío en las ideas. Que se reconozca obligada a padecer por los que le dieron la vida, y purificándose ella, nos ayuda, a los que fuimos malos, a obtener el perdón... (Electra, IV, vi)

También es esencial el personaje de Máximo en la trama. Máximo es el sobrino de Evarista y ha quedado recientemente viudo y con tres hijos a su cargo, uno de ellos un bebé de corta edad, con los que Electra, con su carácter infantil y despreocupado, conecta desde un principio hasta el punto de llegar a secuestrar a uno de ellos con idea de cuidar de él. Además, Máximo, al que apodan el Mágico Prodigioso, es un hombre de ciencia de gran inteligencia y siempre enfrascado en sus experimentos. No hay tampoco que olvidar la importancia de otro personaje de la obra como es el Marqués de Ronda, amigo de los Yuste, pero con unas ideas más liberales. 
Tras estas revelaciones de supuesta paternidad, Electra se mostrará desorientada y desconcertada, por lo que su comportamiento se volverá más infantil con objeto de poder volverse a encontrar con el fantasma de su madre que, cuando era pequeña, se le aparecía para guiarla (Electra II, v). De nuevo, volvemos a ver en este acto un nuevo atisbo de la paternidad de Cuesta, al afirmar este que “QQué felicidad la mía si pudiera quererla públicamente!" (Electra II, xi). Termina este segundo acto con el "secuestro" del hijo de Máximo por parte de Electra, antes mencionado, en un intento por parte de esta de que no sufra la ausencia de madre, ocupando ella dicho puesto.

Empieza entonces a cocerse a fuego lento la relación de amor entre Máximo y Electra en el laboratorio de este, donde ella le está ayudando con la casa y los experimentos a escondidas de sus tíos, que no aprueban que una mujer joven esté en casa de un hombre. Allí, Electra mantiene una larga conversación con Máximo donde le hace partícipe de los miedos que le provoca Pantoja y de la poca importancia que le da a los hombres que la rondan. Es en esta escena donde puede observarse la visión de Máximo sobre Electra y donde puede ya entreverse el amor que empieza a sentir por ella.

Máximo. ¡Singular caso! Cada palabra, cada gesto, cada acción de esta preciosa mujercita; en la libertad de que goza, son otros tantos resplandores que arroja su alma inquieta, notablemente ambiciosa, ávida de mostrarse en los afectos grandes y en las virtudes superiores. (Con ardor.) ¡Bendita sea ella que trae la alegría, la luz, a este escondrijo de la ciencia, triste, obscuro, y con sus gracias hace de esta aridez un paraíso! ¡Bendita ella que ha venido a sacar de su abstracción a este pobre Fausto, envejecido a los treinta y cinco años, y a decirle: "no se vive sólo de verdades...!". (Electra, III, iv)

Por lo que poco después (Electra III, vi) resuelve pedirle matrimonio para que ella pueda dejar de depender de sus tíos y, por ende, de Pantoja. Tras la "bendición" del Marqués y tras el enfrentamiento entre Máximo y Pantoja por la "posesión" de Electra (Electra III, x), ambos deciden ir a anunciar a los Yuste su unión. No obstante, Pantoja, que desea que Electra entre en el convento de San José de la Penitencia, urde un plan consistente en hacerle creer que Máximo y ella son hermanos por parte de madre (Electra IV, vii) con objeto de que ella se sienta perdida e ingrese de forma voluntaria en el convento (Electra IV, xi-xii). Ya en el último acto, Cuesta fallece, dejándole la mitad de sus bienes a Electra, pero con la condición de que abandone el convento. Asimismo, se descubre que todo era una invención de Pantoja (Electra V, iii), aunque Electra sigue sin aceptar las nuevas versiones, aún conmocionada por la "revelación de Pantoja". Por lo tanto, Máximo y el Marqués planean sacarla del convento con la ayuda de la hermana Dorotea, que también quiere huir. Ya, en la última escena, se produce el deus ex 
machina: el fantasma de Eleuteria se aparece y le revela a Electra que todo lo que Pantoja le contó era mentira.

Sombra. Tu madre soy, y a calmar vengo las ansias de tu corazón amante. Mi voz devolverá la paz a tu conciencia. Ningún vínculo de naturaleza te une al hombre que te eligió como esposa. Lo que oíste fue una ficción dictada por el cariño de traerte a nuestra compañía y al sosiego de esta santa casa [...] Acepta, hija mía, como prueba del temple de tu alma, esta reclusión transitoria, y no maldigas a quien te ha traído a ella... Si el amor conyugal y los goces de la familia solicitan tu alma, déjate llevar de esta dulce atracción, y no pretendas aquí una santidad que no encontrarías. Dios está en todas partes... Yo no supe encontrarle fuera de aquí... Búscale en el mundo por senderos mayores que los míos... (Electra $\mathrm{V}, \mathrm{ix})$

Finalmente, Electra huye del convento o, como dice Máximo: "Resucita" (Electra $\mathrm{V}, \mathrm{x})$.

\section{DifERENCIAS Y SEMEJANZAS CON LA(s) Obra(s) Clásica(s)}

Aunque en una primera lectura nos pudiera parecer que los elementos de la Electra(s) clásica(s) no están presentes en la obra, si nos fijamos bien, estos aparecen de forma más o menos velada.

Ya en la segunda escena del primer acto, el Marqués de Ronda nos explica su historia y el porqué del apelativo de Electra. Allí nos cuenta que es un apodo "heredado" de su madre, que se llamaba Eleuteria, por tener un padre militar, muy valiente, desgraciadísimo en la vida conyugal al que apodaron Agamenón. Así pues, el propio Marqués denomina a esta Electra Electra II (Electra I, ii), con lo que incluso podríamos pensar que, más que ante una nueva versión del mito, estamos ante una segunda parte, basada en la hija de Electra.

También habría que destacar otro aspecto importante que es la virginidad de Electra, en este caso motivada por el carácter infantil o infantiloide de la protagonista, amén de su juventud y su soltería, en lugar de por la pesadumbre y la reclusión, en el caso de Sófocles o del matrimonio no consumado, en la obra de Eurípides.

Apunta Iglesias Zoido (2006: 463) que esta Electra recuerda más a la “sacrificada” Ifigenia que a la férrea hija de Agamenón. No obstante, debemos desestimar la idea de encontrarnos con una Electra abnegada o sacrificada. $\mathrm{Si}$ bien es verdad que, tras la falsa revelación de Pantoja, Electra pierde la cabeza ante la idea de amar a su propio hermano, durante toda la obra vemos a una Electra rebelde, que lucha por lo que quiere y que no acepta ser el "ángel” en que Pantoja quiere convertirla, como puede verse en los siguientes fragmentos:

Electra. (Se levanta con grande agitación. Alejándose de Pantoja, exclama aparte:) ¡Dos, Señor, dos protecciones! Y ésta quiere oprimirme. ¡Horrible confusión! 
(Alto.) Señor de Pantoja, yo le respeto a usted, admiro sus virtudes. Pero su autoridad, sobre mí, no la veo clara, y perdone mi atrevimiento. Obediencia y sumisión no debo más que a mi tía. (Electra I, xi)

Electra. Tú me aconsejaste que me insubordinara.

Máximo. Sí tal: yo he sido el instigador de tu delito, y no me pesa.

Electra. Mi conciencia me dice que en esto no hay nada malo. (Electra III, i)

No encontramos, pues, con una Electra que se insubordina ante los deseos de Pantoja y de sus tíos y, por tanto, no debemos quedarnos con la imagen de una Electra abnegada o sacrificada. Es más, es capaz de ser feliz y buscar la felicidad a pesar de las desgracias que ha vivido y que le rodean. Es, en cierto sentido, una obra con un cariz feminista bastante fuerte, lo cual nos retrotrae en parte a la(s) obra(s) clásica(s), aunque denominarlas a estas "feministas" sea anacrónico. Este cariz feminista, que veremos más a continuación, tiene sentido, habida cuenta de la amistad o relación sentimental que unía a Galdós con Emilia Pardo Bazán.

Si nos colocamos en el lado de las diferencias, estas son muchas: esta Electra no tiene madre o padre, cuando uno de los leitmotiv de la obra original es el adulterio de la madre, Clitemnestra, y el posterior asesinato de Agamenón. En este caso, la madre es un ser fantasmal, pues ya está muerta al principio de la obra, a la que Electra (o, mejor dicho, Electra II) adora y a la que le pide consejo cuando no sabe qué hacer. Como antes hemos referido, creemos que Galdós ha querido, más que reescribir la historia, hacer una segunda parte de esta, basada en la hija de Electra.

Otra de las diferencias con respecto a la(s) obra(s) clásica(s) es que Electra no tiene hermanos. Este hecho no es baladí, ya que Orestes juega un papel fundamental en todas las versiones de la obra como mano ejecutora de la venganza. Sin embargo, en esta ocasión, al no existir venganza contra la madre, puede pensarse que no es necesario, por lo tanto, la mano ejecutora. Con todo, es verdad que, durante las escenas finales del acto IV y todo el acto V, Electra considera que Máximo es su hermano y, como puede verse en estas escenas, es él el que se convierte en esa mano ejecutora, solo que esta vez las iras no se dirigen hacia la madre y su amante, sino hacia Pantoja, uno de los posibles padres de Electra. Se produce nuevamente una conjura de los hijos hacia los padres ocupando Máximo el papel de un Orestes vengativo y Pantoja, el de Egisto (Iglesias Zoido 2006: 465-466).

Sin embargo, Finkenthal (1980: 138) encuentra un mayor paralelismo entre las figuras de Orestes y de Pantoja, al considerar que ambos son víctimas de un concepto erróneo de la religión, pues "el crimen que cada uno comete es peor que el que debe ser vengado. Pantoja interpreta la ley divina a su modo. Argumenta que Electra debe espiar [sic] los pecados de sus padres siendo enterrada viva en un convento" (Finkenthal 1980: 138). Asimismo, Finkenthal (1980: 137) sugiere un paralelismo entre Clitemnestra y Eleuteria, entre el adulterio y la vida 
licenciosa de la segunda. Con todo, aceptando que Pantoja fuera el verdadero padre de Electra - aunque me inclino más a pensar que el padre realmente es Cuesta, aunque verdaderamente el interés consiste en que nunca se llega a saber realmente quién es el auténtico padre de la protagonista-, este ocuparía entonces el papel de Egisto, como ha apuntado anteriormente Iglesias Zoido, más que el de Orestes, como indica el propio Finkenthal.

\section{Temática}

Como hemos visto en los puntos anteriores, la Electra de Galdós es una especie de segunda parte de la(s) obra(s) clásica(s) que, a su vez, es hija de su tiempo, tratando temas que son muy importantes en la España de los albores del s. XX. No es de extrañar, por tanto, que la obra, a pesar de que para algunos no está considerada como una de las obras más importante de Galdós (López Nieto 1990: 711), contara con un éxito y un impacto incuestionables con protestas callejeras liberales o anticlericales, prohibiciones de los arzobispos de Sevilla y Oviedo, provocando incluso la caída del Gobierno y la creación del "Ministerio Electra", etc. La obra se tradujo para su representación al alemán, inglés, portugués, neerlandés y francés (López Nieto 1990: 711), representaciones que obtuvieron un gran éxito (Iglesias Zoido 2006: 461) con, por ejemplo, 180 representaciones en París y 32 en Roma (Finkenthal 1980: 111).

Así pues, la crítica respondió de la misma manera, ya que mientras algunos la calificaron de "alegato anticlerical o partidista", otros, entre ellos la prensa liberal de la época, la consideraron "una defensa de los valores del liberalismo, del librepensamiento, de la causa de la libertad y el progreso" (López Nieto 1990: 711, 724-726).

Al respecto de la obra, Pérez Galdós expresó en el Diario de las Palmas el 7 de febrero de 1901 (Finkenthal 1980: 112):

En Electra puede decirse que he condensado la obra de toda mi vida, mi amor a la verdad, mi lucha constante contra la superstición y el fanatismo y la necesidad de que olvidando nuestro desgraciado país las rutinas, convencionalismos y mentiras, que nos deshonran y envilecen ante el mundo civilizado, puede realizarse la transformación de una España nueva que, apoyada en la ciencia y en la justicia, puedan resistir las violentas de la fuerza bruta y las sugestiones insidiosas y malvadas sobre las conciencias.

Si nos centramos en los personajes, vemos como estos cumplen con los arquetipos ideológicos de segmentos de la sociedad de la Restauración, salvo del proletariado con el que Galdós aún no estaba muy sensibilizado (Inman Fox 1970-71: 617). Así, Pantoja sería un carlista ultramontano o el prototipo 
de jesuita; Evarista y Urbano, conservadores clericales; Cuesta y el Marqués, liberales moderados, y Máximo, liberal radical o republicano (López Nieto 1990: 723). Electra, por su parte, se erigirá como símbolo de una España que, como hemos visto, todos quieren dominar a su forma. Es bastante elocuente, aquí, la escena del ángel citada anteriormente (Electra I, xi).

Esta representación de Electra como España se ve claramente en multitud de detalles. Por ejemplo, todos los nombres femeninos de la familia de Electra empiezan por e como son Eleuteria, Evarista y, por supuesto, Electra. Además, Electra es descrita, como hemos dicho anteriormente, como una niña "pura", con problemas familiares (pensemos en todas las rencillas de la España —o de las Españas- de la época en un siglo XIX repleto de guerras civiles) y multitud de fantasmas pasados (la historia) cuyos pecados ella ha de purgar (leyenda negra, herencia recibida tras la pérdida de las últimas colonias, situación social de principios del siglo XX).

Además, como refiere Sobejano (1970: 49):

Generalmente la figura protagónica que encarna el más alto valor moral [en los dramas galdosianos] es una mujer [...]. Lo ordinario es que la mujer ejerza la fuerza más trascendental, aquella mediante la cual se exalta la autenticidad de la persona ética [...] o el ideal ejecutivo [...]. Son mujeres espirituales y prácticas, en tanto los hombres, a menudo, aparecen como sujetos de una espiritualidad inoperante o como juguetes de la duda y de la indolencia. Al fondo de sus creaciones Galdós siempre parece tener presente a España (a Electra) como novia, mujer o madre, y es España la silueta que se dibuja detrás de esos nombres femeninos que cifran la voluntad, la libertad, la acción útil, el amor a la vida, el aliento, la economía, la largueza, el sacrificio. Casi todas esas mujeres son jóvenes, pero sensatas, conscientes y amorosas.

Y, he aquí otro de los temas tratados por Galdós en Electra: el papel de la mujer. Quizá sería muy osado por nuestra parte hablar de Electra como una obra feminista. Sin embargo, sí es verdad que incluye elementos muy avanzados para la época: Electra es una mujer joven que ansía ser libre y que no solo aspira, sino también, a ser madre y esposa, por lo que tiene una serie de motivaciones intelectuales que van más allá, como puede verse a principios del acto III, donde observamos a una Electra que ayuda a Máximo en su laboratorio (Electra III, i) aun rebelándose contra los deseos de sus tíos. Es en esa escena donde Máximo, que como hemos visto refleja esa España moderna y científica, habla de la liberación de la mujer de una forma bastante directa.

Electra. (Muy satisfecha.) ¿Verdad, Máximo, que no soy absolutamente, absolutamente inútil?

Máximo. (Mirándola fijamente.) Nada existe en la creación que no sirva para algo. ¿Quién te dice a ti que no te crió Dios para grandes fines? ¿Quién te dice 
que no eres tú...?

Electra. (Ansiosa.) ¿Qué?

Máximo. ¿Un alma grande, hermosa, nobilísima, que aún no está medio ahogada... entre el serrín y la estopa de una muñeca? (Electra III, i)

Pero no es solo Máximo quien anima a Electra a rebelarse o la incita a liberarse; ella resurge como un personaje con voz propia, con capacidad para tomar decisiones y que se cuestiona los porqués de las convenciones sociales del momento y de su propio rol como mujer.

Electra. Dios, que ve los corazones, sabe que en esto, no hay ningún mal. ¿Por qué no han de permitirme que este aquí todo el día, cuidándote, ayudándote...? Máximo. (Volviéndose con el crisol que ha elegido.) Porque eres una señorita, y las señoritas no puede permanecer solas en casa de un hombre, por muy decente y honrado que éste sea.

Electra. ¡Pues estamos divertidas, como hay Dios, las pobres señoritas! (Electra III, i)

No obstante, debido a las limitaciones de la época, no podemos esperar una Electra liberada en su plenitud: ella sigue teniendo valores y conocimientos de una buena ama de casa, como puede verse en sus facultades de "buena madre" (cocina, cuidado de los niños, etc.) (Electra III, iv y vi), aunque también posee cualidades consideradas "masculinas" como es la capacidad de elegir un buen vino (Electra III, vi).

Es en este tercer acto donde vemos una de las escenas más simbólicas y "románticas" de la obra: la fusión de los metales que será la perfecta metáfora de la futura unión de los dos amantes. Si vemos este acto en perspectiva, en un principio ellos se comparan con los metales que van a fundirse:

Electra. ([...] Al verter el metal en la cápsula, admira su belleza.) ¡Qué bonito! ¿Qué es esto?

Máximo. Aluminio. Se parece a ti. Pesa poco...

Electra. ¿Que peso poco?

Máximo. Pero es muy tenaz (Mirándole al rostro.) ¿Eres tú muy tenaz?

Electra. En algunas cosas, que me reservo, soy tenaz hasta la barbarie, y creo que, llegado el caso, lo sería hasta el martirio (Sigue pesando sin interrumpir la operación.)

Máximo. ¿Qué cosas son ésas?

Electra. A ti no te importan.

Máximo. (Atendiendo al trabajo.) Mejor... En seguidita me pesas 70 gramos de cobre. (Prestándole otro frasco.)

Electra. El cobre serás tú... No, no, que es muy feo.

Máximo. Pero muy útil.

Electra. No, no: compárate con el oro, que es el que vale más. 
Máximo. Vaya, vaya, no juguemos. Me contagias, Electra; me desmoralizas... Electra. Déjame que me recree con las cualidades de este metal bonito, que es mi semejante. ¡Soy tenaz... no me rompo...! Pues bien, puedes decírselo a Evarista y a Urbano, que en el sermón que me echaron dijéronme como unas cuarenta veces que soy... frágil... ¡Frágil, chico! (Electra III, i)

Así pues, conforme vaya avanzando el acto, se producirá un claro simbolismo entre las fases de calentamiento y fusión de los metales y las fases por las que pasarán los amantes. Esto puede verse en la pequeña reprimenda que le echa Máximo a Gil por estar distraído (Electra III, ii), de la misma forma que a él le "distraen" las locuras e ideas de Electra; en la confesión de Máximo a Gil (Electra III, v) y en el monólogo de Máximo sobre la necesidad de amor y humanidad en el ser humano más allá de la ciencia, que reproduzco a continuación:

Gil. [...] Distraído yo, confundí la cifra de la potencial con la de la resistencia... Pero ya rectifiqué... Dígame si está bien.

Máximo. (Lee.) 0,318,73 (Con repentina transición a un gozo expansivo.). Y si no lo estuviera, Gil; si por refrescar tu mente con ideas dulces, con imágenes sonrosadas, poéticas, te hubieras equivocado, ¿qué importaba? Nuestra maestra, nuestra tirana, la exactitud, nos lo perdonaría.

Gil. ¡Ah! señor, esa no perdona. Es muy severa. Nos agobia, nos esclaviza, no nos deja respirar.

Máximo. Hoy no: hoy es indulgente. La maestra, de ordinario tan adusta, hoy nos sonríe con rostro placentero. ¿Ves esa cifra?

Gil. (Diciéndola de memoria muy satisfecho.) 0,318,73.

Máximo. Pues di que los primeros poetas del mundo, Homero y Virgilio, Dante, Lope, Calderón, no escribieron jamás una estrofa tan inspirada y poética como lo es esa para mí, esos pobres números... Verdad que la armonía, el encanto poético no están en ellos: están en... Vete... Puedes irte a comer... Déjame, déjanos. (Le empuja para que se vaya.) No me conozco: yo también confundo... Lucido estoy con esta inquietud, con esta pérdida de mi serenidad. Es ella la que... (Desde el punto conveniente de la escena mira al interior.) Allí está la imaginación, allí el ideal, allí la divina muñeca, entre pucheros... (Vuelve al proscenio.) ¡Oh! Electra, tú, juguetona y risueña, ¡cuán llena de vida y de esperanzas; y la ciencia qué yerta, qué solitaria, qué vacía!

También es de destacar cómo, después de la "pedida de mano" de Máximo a Electra (Electra III, vi), la fusión se encuentre "al rojo vivo" (Electra III, viii) y que después de recibir la bendición por parte del Marqués de Ronda, esta haya alcanzado el "blanco incipiente" (Electra III, ix) — una clara alegoría del traje de novia de Electra-. Finalmente, tras el enfrentamiento entre Máximo y Pantoja sobre Electra (Electra III, x), la fusión de los metales está "blanco deslumbrante". Es entonces cuando el que responde a Mariano, el operario, no es Máximo, sino el Marqués con un sucinto, aunque elocuente: "La fusión está hecha” y, justo después de esta réplica, 
Máximo le dice a Electra que va a reclamar su mano ante sus tíos. El acto acaba con una réplica de Electra: "Es el día... ¡Día eterno para mí!” (Electra III, xi)

Este acto de la fusión de los metales como símbolo de la unión entre los amantes es considerado por Inman Fox como "fusión sana de los intereses económicos" (1970-1971: 617) y lo compara con las representaciones de las masas en Las de San Quintin o el amor entre Pascual, el pastor-revolucionario, y la duquesa de Ruydíaz en Alma y día. Por su parte, Finkenthal (1980: 136) ve a Electra como símbolo de la electricidad por su compartimento aparentemente desenfadado y por el hecho de que el laboratorio de Máximo se dedica, precisamente, a estudiar la electricidad.

Volviendo al tema social anteriormente presentado, es de rigor observar que no es una obra "revolucionaria", como afirmó el propio Galdós (López Nieto 1990: 721), sino una obra que defiende el orden social de la Restauración frente a los extremismos y una victoria del pensamiento liberal avanzado y del sentimiento religioso progresista (López Nieto 1990: 717). Esto puede verse claramente en una escena entre el Marqués y Máximo en el acto V.

Máximo. [...] (Exaltándose más.) A ese hombre [Pantoja], a ese monstruo... hay que matarlo.

marqués. No tanto, hijo. Imitémosle, seamos como él astutos, insidiosos, perseverantes.

Máximo. (Con brio y elocuencia.) Seamos como yo, sinceros, claros, valientes. Vayamos a cara descubierta contra el enemigo. Destruyámosle si podemos, o dejémonos destruir por él... pero, de una vez, en una sola acción, en una sola embestida, en un solo golpe... O él o nosotros.

Marqués. No, amigo mío. Tenemos que ir con pulso. Es forzoso que respetemos el orden social en el que vivimos.

Máximo. Y este orden social en que vivimos los envolverá en una red de mentiras y de argucias, y en esa red pereceremos ahogados, sin defensa alguna... manos y cuello cogido en las mallas de mil y mil leyes caprichosas, de mil y mil voluntades falaces, aleves, corrompidas. (Electra $\mathrm{V}, \mathrm{v}$ )

Como puede verse en este fragmento, mientras Máximo es más partidario de una revolución o revuelta (llegará a afirmar poco después que podría incluso "pegar fuego a Madrid"), Marqués es un hombre más cabal, que se deja llevar menos por los impulsos primarios y que es firme partidario de respetar el orden social establecido, tesis que se revela finalmente como la mejor y la que logra el éxito. Es de rigor decir que Pérez Galdós aún no había evolucionado hacia el republicanismo, aunque en palabras de Botrel (1977): "Galdós sigue siendo para los sectores católicos, conservadores y tradicionalistas el enemigo de siempre, de antes de Electra y de después, y para los partidos obreros o radicales un burgués arrepentido, incluso de su anterior republicanismo".

Otro de los asuntos más importantes tratados en la obra es el de Dios o, mejor dicho, de la tolerancia religiosa. No estamos, ni mucho menos, ante una 
obra atea o que haga "apología del ateísmo"; Dios está presente de forma positiva incluso en los personajes más progresistas como pudieran ser el Marqués, Máximo o la propia Electra. Por lo tanto, no es extraño ver durante la obra momentos en los que algunos de estos personajes se encomienden a Dios con la idea de que obre justicia. Este es, según Finkenthal (1980: 137-138), uno de los puntos que más unirá esta obra con la(s) antigua(s).

Así pues, como afirma López Nieto (1990: 715) estamos ante una obra que pregona la tolerancia religiosa, tesis apoyadas por las opiniones de Máximo, Electra, el Marqués, Cuesta e incluso Evarista y Urbano en su enfrentamiento con Pantoja. No en vano, como afirma el propio López Nieto (1990: 716):

Máximo y Pantoja (apoyados o matizados por el Marqués de Ronda y Evarista) representan [...] los dos polos opuestos en una disputa en la que se debaten cuestiones como el verdadero sentimiento religioso y la libertad de conciencia frente a los peligros del fanatismo y la intransigencia; la idea de Dios - y una religión - tolerante, bueno, amable... frente a la concepción de un Dios - $y$ una religión - intolerante, duro...; la denuncia de la imposición de la vida religiosa y la muestra de la posibilidad de alcanzar la salvación también en el mundo; la denuncia del aumento del poder, de la creciente influencia del clericalismo; la negación de la validez del uso de cualquier medio para conseguir el fin deseado; y la contraposición entre ciencia (progreso) y fe (tradición), entre otros temas de menor importancia.

Por último, hablaremos del final de la obra, un final que ha sido bastante vilipendiado por algunos críticos. En la penúltima escena de la obra (Electra V, ix), a Electra se le aparece el fantasma de su madre, quien le dice que no existe ningún vínculo familiar entre Máximo y ella y que la motivación de Pantoja vino dictada por el cariño y no por la maldad. Finalmente, le pide que encuentre a Dios donde mejor pueda encontrarlo - ya sea en el amor conyugal o en la santidad de la reclusión monástica- Como podemos ver, el fantasma de la madre trasmite un mensaje de tolerancia, reconciliación y paz sin rencillas en Electra (y, por ende, en España), una España/Electra dirigida o comandada por la burguesía y la aristocracia liberal (López Nieto 1990: 724) y que, como se ve en las palabras finales, "No huye, no, resucita" (Electra V, x). Es, por tanto, un final optimista: es posible la salvación de España.

Sin embargo, llama la atención el uso de este recurso (el deus ex machina) en una obra tan progresista, podríamos llamarla, y que elogia tanto a la ciencia. No obstante, cabe rescatar que no estamos ante una obra "atea", sino en una donde se habla de la tolerancia religiosa y donde se hace hincapié en que, parafraseando la máxima bíblica, "no solo de ciencia vive el hombre". Además, como afirma Finkenthal (1980: 146), desde un punto de vista teatral, esta aparición fantasmal no entra en conflicto con la verosimilitud de la trama, ya que esta no es más 
que un reflejo de la conciencia de Electra y, como señala Sobejano (1970: 47), Galdós, aunque realista, no se deja encasillar e introduce elementos prodigiosos en algunas de sus obras (como Realidad), del mismo modo que hacían sus contemporáneos Ibsen, Hauptmann o Strindberg.

Así pues, el final parece bastante más lógico con respecto a la obra de lo que cabría esperar en un primer momento y en el que, aunque Iglesias Zoido (2006: 465) ve claramente la influencia de Hamlet, nosotros encontramos que estamos más hacia un nuevo elemento que une la Electra galdosiana con la(s) Electra(s) clásica(s), como puede ser el final de la Electra de Eurípides con las Furias.

\section{Conclusiones}

Aunque en una rápida lectura parezca que no queda nada de la(s) Electra(s) clásicas en la obra de Galdós, hemos podido analizar cómo permanecen en la obra muchos elementos que relacionan directamente a esta Electra con sus antepasadas como son los paralelismos entre personajes como los de Máximo y Orestes o como entre Egisto y Pantoja. Así, más que una reescritura del mito, Galdós ha optado por hacer una segunda parte, una Electra II, que bebe directamente de los conflictos sociales y culturales de la España de después de la pérdida de Cuba y Filipinas, entre los que encontramos un incipiente feminismo y una búsqueda de la tolerancia religiosa, entre otros, en un país donde la influencia de la jerarquía eclesiástica católica ha sido tradicionalmente tan fuerte.

Existe una clara relación entre Electra y España, ambas en conflicto y ambas obligadas a purgar los pecados de generaciones anteriores (recordemos las tres guerras civiles del s. XIX en España). Ambas han de sufrir la polarización entre aquellos que la quieren convertir en su ángel, como Pantoja, y aquellos que la quieren libre, como Máximo. El final no podría ser más esperanzador: se busca una reconciliación entre las dos España (tal como afirma el fantasma de la madre de Electra) y una paz sin rencillas. En este sentido, las palabras de Máximo que cierran la obra no podrían ser más elocuentes: no nos encontramos ante una huida, sino ante una resurrección.

Estamos, pues, ante una obra muy interesante, no solo para entender el mito de Electra, sino la situación de una España que estaba renaciendo (resucitando) ante el progreso. Galdós, gran conocedor de la historia de España, supo plasmar en sus réplicas un interesante conflicto entre pasado y futuro, entre tradición y modernidad, entre religión y ciencia y, sobre todo, entre perdón y rencor. Desgraciadamente, ese futuro idílico y utópico no llegaría a concretarse y la obra fue objeto de multitud de críticas provenientes, sobre todo, de las élites más conservadoras (o "pantojiles"). 
Electra, Dios y Galdós: comparativa y temática de una Electra en los albores del siglo XX

\section{Bibliografía}

Ávila Arellano, Julián (1992). El personaje femenino en la obra de Galdós (una aproximación al simbolismo historico del escritor). Madrid: Universidad Complutense de Madrid.

Botrel, Jean François (1977). Benito Pérez Galdós, ¿escritor nacional? En: Actas del Primer congreso internacional de estudios galdosianos. [http://www. cervantesvirtual.com/obra-visor/benito-prez-galds-escritor-nacional-0/ html/ffd60992-82b1-11df-acc7-002185ce6064_8.html\#I_2_]

Escolar, Arsenio (1989). «Las mujeres de Galdós». Cambio 16. 30 de enero de 1989.

Finkenthal, Stanley (1980). El teatro de Galdós. Jesús, Bruno de (trad.). Madrid: Fundamentos.

Inman Fox, Edward (1970-71). "En torno a "Mariucha": Galdós en 1903". Cuadernos Hispanoamericanos 250-251-252. 608-622.

Iglesias Zoido, Juan Carlos (2006). "Anagnorisis en la Electra de B. P. Galdós". Bulletin Hispanique 2. 459-474.

López Nieto, José Carlos (1990). «Electra o la victoria liberal. (Una nueva interpretación a la luz de la situación histórica española de hacia 1900)». En Actas del IV Congreso Galdosiano. 711-730.

Sobejano, Gonzalo (1970). "Razón y suceso de la dramática galdosiana”. Anales galdosianos. 39-53. 